\title{
A pan-London approach to patient group directions in sexual health services: from aspiration to reality
}

\author{
Angela Bussey, ${ }^{1}$ Kathy French ${ }^{2}$
}

\begin{abstract}
${ }^{1}$ Principal Pharmacist Medicines Information Projects, Guy's and St Thomas' NHS Foundation Trust, Guy's Hospital, London, UK

${ }^{2}$ Independent Nurse, London Sexual Health PGD Project Lead, London UK
\end{abstract}

\section{Correspondence to}

Mrs Angela Bussey, Guy's and St Thomas NHS Foundation Trust - Medicines Information, Pharmacy Department, Guy's Hospital, Great Maze Pond, London SE1 9RT, UK; angela.bussey@gstt.nhs.uk

Published Online First 29 November 2016

\section{CrossMark}

To cite: Bussey A, French $K$.

J Fam Plann Reprod Health

Care 2017:43:154-156.

\section{BACKGROUND}

A patient group direction (PGD) is a legal mechanism $^{1}$ that allows the supply and/or administration of a specified medicine or medicines, by named authorised health professionals, to a well-defined group of patients requiring treatment for the condition described in the PGD without the need for a prescription or an instruction from a prescriber. Using a PGD is not a form of prescribing. ${ }^{2}$

Whilst prescribing remains the preferred option for the majority of care, ${ }^{2}$ sexual health services have been dependent on this legal mechanism to supply and administer medicines in the absence of timely access to a prescriber for many years.

For example, medicines may be supplied by registered nurses or pharmacists to people attending for contraception or for other unscheduled care in a sexual health clinic or in a community pharmacy for a discrete treatment episode, such as emergency contraception or treatment for chlamydia.

Whilst nurses and pharmacists may now train to become independent nonmedical prescribers in their own right, many services still rely on PGDs to deliver the service.

\section{WHY WAS CHANGE NEEDED?}

Prior to 2011, contraceptive and sexual health service providers in London developed their own PGDs. It became apparent from discussions with lead nurses and doctors within the services that there were problems due to the many different versions being used and the human resource needed to develop/review PGDs on a regular basis. There was a risk of inconsistent standards of care and risks associated with practice where nurses employed in more than one organisation had to work to different PGDs. At that time, it was calculated that there were at least 30 versions of each PGD.

The medical lead and nurse advisor for the London Sexual Health Programme (LSHP) called a meeting with National Health Service London pharmacy leads. The key purpose of the meeting was for the LSHP to share, with pharmacy colleagues, the current position around the difficulties involved, and the potential impact on patient care and workload.

It was agreed that a pan-London approach to developing a set of PGD templates for hormonal contraceptives and for treatments of common sexually transmitted infections (STIs) would help to ensure consistent standards of practice across London and provide a safer, more accessible and effective service to users.

\section{HOW DID WE GO ABOUT}

\section{IMPLEMENTING CHANGE?}

Having gained agreement at a Londonwide meeting with stakeholders including clinicians and commissioners, the nurse advisor for LSHP became the project lead and a specialist pharmacist agreed to provide PGD and governance advice to the project. Colleagues committed to membership of the multidisciplinary working group which included two nurses, two doctors and three pharmacists. This group became the London Sexual Health PGD Group and terms of reference were agreed.

There were two separate working groups for contraception and STIs. This was the most effective use of the group members' skills. To ensure compliance with PGD legislation ${ }^{1}$ and best practice, ${ }^{2}$ each clinical group consisted of a senior doctor and senior pharmacist as well as a specialist nurse and a community pharmacist, representing the professional groups who would use the PGDs. The project 
lead and governance lead provided the necessary oversight to both groups.

A formal written process was agreed to ensure that legal and national guidance requirements for development of the templates could be met. ${ }^{2}$

With the process and terms of reference agreed, a blank PGD template document was developed so that each template could include all the information that is legally required for a PGD and to ensure a consistent format across the set of templates.

PGD templates were written with reference to best available evidence and national clinical guidelines, with consideration given to referral pathways and to 'gold standards' for the training and competency of practitioners working with the PGDs. The templates were circulated via various lead nursing, medical and pharmacy networks for feedback and comments by an agreed date, usually 10 working days.

Comments received were collated and amendments were made to the templates as required. The group found that the most efficient way of working was to agree any amendments and final documents at faceto-face meetings.

A set of 11 contraceptive PGD templates were published in April 2012 and this was followed by a set of STI templates in May 2012.

To comply with National Institute for Health and Care Excellence (NICE) Patient Group Directions Medicines Practice Guideline (MPG2) ${ }^{2}$ and also updated clinical information ${ }^{3-6}$ all PGD templates have undergone review and update in the last 2 years. Several new PGD templates have also been developed. The templates and related process documents are published on the Specialist Pharmacy Service website. ${ }^{7}$

By 2015 there were 31 templates available for nurses and community pharmacists in London (Table 1).

\section{WHAT WERE THE OUTCOMES OF THE CHANGE IN PRACTICE?}

Providers and commissioners have recognised that adopting the PGD templates provides a consistent and

Table 1 Patient group direction templates available for nurses and community pharmacists in London, UK

\begin{tabular}{lll}
\hline Type of PGD & $\begin{array}{l}\text { Professional } \\
\text { group }\end{array}$ & $\begin{array}{l}\text { Templates } \\
(\mathrm{n})\end{array}$ \\
\hline $\begin{array}{l}\text { Contraceptive methods/emergency } \\
\text { contraceptives/lidocaine for } \\
\text { subdermal implant insertion }\end{array}$ & Nurses in SRH & 14 \\
$\begin{array}{l}\text { Treatment of common STIs } \\
\text { Emergency contraceptives and }\end{array}$ & $\begin{array}{l}\text { Nurses in SRH } \\
\text { Community } \\
\text { contraceptive methods }\end{array}$ & 11 \\
Treatment of common STIs & $\begin{array}{l}\text { Community } \\
\text { pharmacists }\end{array}$ & 2 \\
\hline
\end{tabular}

PGD, patient group direction; SRH, sexual and reproductive health; STI, sexually transmitted infection. high standard of care no matter where a patient presents for treatment.

Colleagues have recognised that the development of a set of PGD templates is also a more efficient way of working, preventing duplication of effort and representing a more effective use of clinical resource by adopting a 'do once and share' approach.

\section{WHAT CHALLENGES DID WE FACE?}

Formal, clinical authorisation of PGD content is not possible under current arrangements. It has thus remained the responsibility of the organisations who wanted to use the templates to ensure that authorisation and use of PGDs for their services was appropriate and legal.

In April 2013, when new commissioning arrangements came into force, LSHP was abolished and there was no sexual health lead in post. This presented a risk to the future of the project; however, we gained the support of the new Lead Sexual Health Commissioner and public health colleagues. Work began again in 2014 under new commissioning arrangements.

Since 2013, there has been an increased pressure on services and workload implications that impacts on the capacity of colleagues to support the London Sexual Health PGD group. Economic pressures are also a risk to the future viability of this work.

If the PGD templates are not updated and reviewed, this means reverting to local arrangements, which not only creates a less favourable outcome for patient care, but also requires local resource to be taken from the front line for this 'back office' clinical work.

\section{WHAT ADVICE WOULD YOU GIVE TO OTHERS CONSIDERING TAKING SIMILAR ACTION?}

The development, audit, review and updating of PGD templates is a cyclical process and not a 'project' but an ongoing service. There needs to be strong leadership and a firm commitment to the process, which does not end when a PGD template has been developed. ${ }^{8}$

When working across a number of organisations, formal agreements would better support sustainability of the service with a single operating model for the clinical authorisation of PGD templates. This would further improve efficiency and reduce duplication of effort.

PGDs can take many hours of work and involve senior clinicians who may be removed from front-line working to write and review PGDs. A multidisciplinary approach involving experts drawn from a range of geographical locations and different services is vital from the outset. ${ }^{2}$

At local service level, it is essential to consider carefully the resources and capacity required to develop and continually review and update PGDs, which is 
vital in ensuring that they remain a safe and appropriate option for patient care. ${ }^{2}$ In some cases it may be better both for patients and the local health economy to introduce a cohort of independent non-medical prescribers within the service and eventually supersede the need for PGDs. ${ }^{2}$

Acknowledgements The authors wish to acknowledge members of the London Sexual Health Working Groups for their dedication and commitment during challenging times, and colleagues across London from nursing, medicine and pharmacy who provide helpful and constructive feedback as part of this robust and often challenging process. A special word of gratitude is due to Peter Taylor, Lead Commissioner for Sexual Health in London, for his support in ensuring the project remained viable after 2013, and to Baroness Gould of Potternewton for supporting the project and the launch in the House of Lords.

Competing interests None declared.

Provenance and peer review Not commissioned; externally peer reviewed.

\section{REFERENCES}

1 legislation.gov.uk. The Human Medicines Regulations 2012. 2012. http://www.legislation.gov.uk/uksi/2012/1916/contents/ made [accessed 28 Sep 2016].

2 National Institute for Health and Care Excellence (NICE). Patient Group Directions. Medicines Practice Guideline (MPG2). 2013. http://www.nice.org.uk/guidance/MPG2 [accessed 28 Sep 2016].

3 British Association for Sexual Health and HIV (BASHH) website. http://www.bashh.org.uk [accessed 28 Sep 2016].

4 Faculty of Sexual and Reproductive Healthcare (FSRH) website. http://www.fsrh.org [accessed 28 Sep 2016].

5 British National Formulary website. https://www.bnf.org/ [accessed 28 Sep 2016].

6 Summaries of Product Characteristics. http://www.medicines. org.uk or http://www.mhra.gov.uk [accessed 28 Sep 2016],

7 Specialist Pharmacy Service website. http://www.sps.nhs.uk [accessed 28 Sep 2016],

8 Specialist Pharmacy Service. Quality PGDs - 7 Steps to Success. 2016. https://www.sps.nhs.uk/articles/quality-pgds-7steps-to-success/ [accessed 28 Sep 2016], 